\title{
Hydraulic fracturing - integrating public participation with an independent review of the risks and benefits
}

David Wheeler ${ }^{\mathrm{a} *}$, Margo MacGregor ${ }^{\mathrm{a}}$, Frank Atherton ${ }^{\mathrm{b}}$, Kevin Christmas ${ }^{c}$, Shawn Dalton ${ }^{\mathrm{d}}$, Maurice Dusseault ${ }^{\mathrm{e}}$, Graham Gagnon ${ }^{\mathrm{f}}$, Brad Hayes $^{\mathrm{g}}$, Constance MacIntosh ${ }^{\mathrm{h}}$, lan Mauro ${ }^{\mathrm{i}}$ and Ray Ritcey

${ }^{a}$ Verschuren Centre for Sustainability in Energy and the Environment, Cape Breton University, 1250 Grand Lake Road, Sydney, Nova Scotia, Canada B1P 6L2

${ }^{b}$ Department of Health and Wellness, Government of Nova Scotia, 6244 Seaforth Street, Halifax , Nova Scotia, Canada B3L 1P9

${ }^{\mathrm{C}}$ Membertou First Nation, 111 Membertou, Sydney, Nova Scotia, Canada, B1S 2M9

${ }^{d}$ Thrive Consulting, 25 Colonial Heights, Fredericton, New Brunswick, Canada E3B 5M3

${ }^{\mathrm{e}}$ Department of Earth and Environmental Sciences, University of Waterloo, 200 University Avenue, Waterloo, Ontario, Canada N2L 3G1

${ }^{f}$ Faculty of Engineering, Dalhousie University, 1360 Barrington Street, Halifax, Nova Scotia, Canada B3J 2X4

${ }^{g}$ Petrel Roberston Consulting Ltd., 500, 736 8th Avenue SW, Calgary, Alberta, Canada T2P $1 \mathrm{H} 4$

${ }^{\mathrm{h}}$ Faculty of Law, Dalhousie University, 6061 University Avenue, Halifax, Nova Scotia, Canada B3H 4R2

'Department of Geography, University of Winnipeg, 515 Portage Avenue Winnipeg, Manitoba, Canada R3B 2E9 
${ }^{j}$ Lighthouse Energy Inc., 1628 Cambridge Street, Halifax, Nova Scotia, Canada B3H 4A7

*Corresponding Author:

Email Corresponding Author. Email: david_wheeler@cbu.ca Office telephone: 902-563-1393

Email Co-authors:

macgregor.margo@gmail.com

frank.atherton@novascotia.ca

kevinchristmas@eastlink.ca

shawn@shawndalton.com

mauriced@uwaterloo.ca

graham.gagnon@dal.ca

bhayes@petrelrob.com

constance.macintosh@dal.ca

i.mauro@uwinnipeg.ca

ray.ritcey@gmail.com

\section{Abstract}

This paper describes a fully independent public participation and review process on the environmental, economic, health, community and social risks and benefits of hydraulic fracturing for the development of unconventional gas and oil resources. We describe the approach taken to maximise public engagement in the process and how that participation informed the work of an independent panel charged with examining the scientific evidence and related legal issues. The major findings from the review are presented, including a risk matrix which summarises the frequency, severity and mitigation measures for sixteen 
potential hazards associated with hydraulic fracturing, as they may pertain to the province of Nova Scotia in Canada. We discuss the complexity of managing public perceptions of novel risks such as hydraulic fracturing and conclude with brief observations on the contribution of the review to public policy.

Keywords: Hydraulic Fracturing; Public Participation; Nova Scotia; Independent Review

\section{Introduction}

\subsection{Hydraulic Fracturing and Public Policy Development}

Advances in unconventional oil and gas production technologies have resulted in a significant increase in development and extraction in North America in recent years (Council of Canadian Academies, 2014). Hydraulic fracturing ${ }^{1}$ is a method of extracting natural gas or oil whereby pressurized fluid (water and additives) is pumped underground under high pressure causing fractures in the geologic formation. Once the fractures are created,

\footnotetext{
${ }^{1}$ For the purpose of this paper we define hydraulic fracturing as: 'the process of hydraulic fracturing and its directly associated activities and technologies for the purpose of unconventional gas and oil development' (Atherton et al., 2014).
} 
proppants are injected into the wells to ensure the fractures stay open allowing oil and gas deposits to flow to the surface (Environmental Protection Agency, 2014).

With the rapidly increasing scale of development globally has come significant controversy over the environmental and social impacts and economic benefits of the technology (Theodori et al., 2014). Public pressure is being placed on governments around the world to either prohibit the process or develop and enforce policies and regulations that protect the environment and communities from any associated risks the technology poses. It has been argued that new governance models (Small et al., 2014) and public participation in the policy development process, coupled with independent scientific research (Jackson et al., 2014), could help governments address the perceived risks and benefits of technologies such as hydraulic fracturing, resulting in stronger and more widely accepted policies and regulations (North et al., 2014).

Holahan and Arnold (2013) place the hydraulic fracturing policy literature into three categories: i) review literature on the rise of shale gas development and regulation which calls for more research into policy implications; ii) articles focusing on public attitudes towards hydraulic fracturing and community responses; and iii) empirical articles pointing to specific environmental and other impacts of hydraulic fracturing. In this section we focus primarily on categories (i) and (ii). In our Results section and our Appendix we address category (iii). Unfortunately for policy makers, much of the existing literature, particularly in the third category, is disputed or challenged on the basis of lack of long term evidence (Council of Canadian Academies, 2014). With a limited amount of peer-reviewed academic literature and with that which does exist often disputed in polemical forums and grey 
literatures, governments are seriously disadvantaged when developing policy on hydraulic fracturing. They are further compromised by the intensity and complexity of interactions of different stakeholders with government and its agencies at multiple levels (Rabe, 2014).

Smith and Ferguson (2013) describe the jurisdictional and stakeholder complexity for hydraulic fracturing policy regulators in the U.S as follows:

Regulating natural gas exploration and extraction is a complex public policy issue. One reason for this complexity is that decisions affecting the outcome of an issue are made at all levels of U.S. government-local, state, and federal. This complexity represents a strategic planning challenge for issue managers working for industry interests, environmentalists, and citizens. While these groups use public relations strategies to pursue their preferred outcome on an issue, they also argue over which government structure or agency is the appropriate place for public policy to be decided.

Policy issues in Canada are equally complex with similar governance challenges at municipal, provincial and federal levels. In common with the US, in Canada: "benefits are mostly regional whereas adverse impacts are mostly local and cut across several layers of government" (Council of Canadian Academies, 2014). But in contrast to the US where the decision to allow exploration and exploitation is made by landowners who own the subsurface rights, in Canada subsurface rights usually belong to the Crown, providing Provincial Governments with the control of development and regulatory processes such as the issuing of exploration licences (Maclntosh, 2014a). However, it should be noted that 
Canada's First Nations title and treaty rights may transcend provincial and federal jurisdiction, creating yet another level of complexity in the Canadian context (Maclntosh, 2014b).

\subsection{Public Participatory Approaches to Energy Policy Development}

Public participatory approaches to policy development have been applied in many fields, including strategic environmental assessments (Gauthier et al., 2011), energy efficiency and renewable energy strategies (Adams et al., 2011; Devine-Wright, 2014; Ngar-Yin Mah and Hills, 2014).

Proponents of public participatory policy development regimes may use different approaches, such as the multi-criterion decision making method (Greening and Burnow, 2004) or a post-normal science (PNS) approach i.e. evidence-based decision-making (Turnpenny et al., 2009). Regardless of the approach, the underlying arguments in favour of a participatory approach are similar: as the public becomes better informed citizens have an avenue to voice their concerns and fears, and when those concerns are addressed and reconciled with scientific evidence, better public policy may be developed.

Policy-making in the field of unconventional oil and gas development has been described as a complex or 'wicked' problem (Mauro, 2014). A wicked problem is one that is difficult to solve using traditional methods of science and governance (Levine et al., 2012). Turnpenny and co-workers (2009) describe how wicked problems may be addressed through 
participatory policy making processes. It is salutary to note their observation that participatory processes do not necessarily predict how political decisions will ultimately be made. However it is clear that in the absence of a participatory process, governments are more likely to make decisions that do not adequately reconcile public concerns with scientific research.

\subsection{Applying Public Participatory Approaches to Hydraulic Fracturing Policy Development in Nova Scotia}

In jurisdictions that have already made significant policy decisions on hydraulic fracturing, decisions have been criticised for: i) focusing more on maximizing extraction than environmental protection (Rabe and Borick, 2013); ii) non-disclosure of chemical use (Heikkila et al., 2014); and iii) insufficiently stringent regulation (Davis and Fisk, 2014). In Nova Scotia, in common with other jurisdictions (Adgate et al., 2014; Small et al., 2014), an extra constraint on policy development is the lack of trust in the environmental responsibility of industry or in the Government to properly "protect both citizens and the environment to ensure economic, social and environmental sustainability" (Nova Scotia Commission on Building Our New Economy, 2014).

When the Province of Nova Scotia decided to commission an independent review of hydraulic fracturing, several western Canadian provincial jurisdictions had significant experience of regulating and developing unconventional oil and gas resources (Canadian 
Association of Petroleum Producers, 2014). However in several eastern provinces, including Nova Scotia, there was a de facto moratorium on the practice.

All onshore oil and gas activity in Nova Scotia is regulated by the Department of Energy, but other departments, such as the Department of Environment (e.g. for permitting to water abstractions) are also involved. The Petroleum Resources Act determines whether petroleum rights may be granted and also gives the Minister of Energy the authority to enact regulations. Other than one statute which bans transporting hydraulic fracturing wastewater into Nova Scotia, there was no relevant prior and specific provincial legislation at the time of the review, although federal legislation has addressed some matters including inter-provincial pipelines and restricted chemicals.

Some preliminary internal research was conducted into hydraulic fracturing by the Department of Energy between 2011 and 2013, including a jurisdictional review and a limited amount of public outreach (Nova Scotia Department of Energy, 2014). However, the policy, regulatory and public engagement context for the review was largely undeveloped.

The Province of Nova Scotia did have one helpful piece of foundational legislation in place termed the Environmental Goals and Sustainable Prosperity Act or 'EGSPA' (Province of Nova Scotia, 2007). EGSPA aims to integrate environmental sustainability with economic prosperity through 'precautionary approaches' (see Section 2.4) leading, for example, to the setting of targets for greenhouse gas emission reductions. This legislation was highly influential in the framing of recommendations from the review. 
At the heart of the design of the review was the importance of drawing together scientific and other forms of knowledge (including Aboriginal wisdom) with public understanding of risk through a participatory process that might prepare the province for more informed decision-making, all within a precautionary approach.

\section{Methods}

\subsection{Mandate from the Province of Nova Scotia}

A mandate was provided to the Verschuren Centre at Cape Breton University by the Province of Nova Scotia which set out the broad scope of an independent review (Atherton et al., 2014). The mandate included: create a panel of technical experts from public nominations and hire technical consultant(s) to facilitate the work of the panel; hire a project administrator to coordinate the review; conduct public consultations on the process of hydraulic fracturing; conduct a literature review on the health and socio-economic impacts of hydraulic fracturing and; prepare a final report to the Government of Nova Scotia with recommendations on the potential risks and benefits of hydraulic fracturing in the Province of Nova Scotia.

\subsection{Approach to Public Engagement}

Following similar steps to Adams and co-workers (2011) and the recommendations of Ricci et al. (2010), the following principles were applied in the development of a public engagement strategy on hydraulic fracturing in Nova Scotia: 
- Public engagement had to be understood and implemented through diverse mechanisms with different levels of participation.

- Engagement needed to range from the simple provision of information to active deliberation to help a heterogeneous public with different levels of knowledge and interest become involved.

- The process needed to be socially inclusive, accessible and informative.

- The process needed to include the issues that people think are relevant; not simply technical questions of economic potential and technological challenges.

- True public engagement requires considering the issue holistically: how would the risks and benefits be distributed and what would developments mean for future generations as consumers, residents and citizens.

Public participation was actively sought during the review following the Adams et al. (2011) approach to energy policy development and the North et al. (2014) recommendations on the potential "benefits of sound dialogue and learning among publics, stakeholders, industry, and regulatory decision makers" in hydraulic fracturing policy development. Every aspect of the review was transparent and open to the public; any individual or group interested in the process was able to register as a stakeholder, participate at any stage and stay current with unfolding events.

Opportunities for engagement in the review included:

- Registering as a stakeholder

- Commenting on skill sets to be incorporated into the selection process for panelists to serve on the Review Panel 
- Nominating candidate Review Panelists

- Bidding for technical advisory work commissioned by the review

- Submitting written evidence

- Participating in on-line discussions and surveys

- Participating in public forums

- Commenting on recommendations

- Providing feedback and commentary on discussion papers issued throughout the review

Discussion papers were authored by panel members and consultants according to their subject matter expertise. Once approved for release by the Panel, a two-three week period was allowed for public comment. The lead author(s) subsequently revised their documents, acknowledging and reflecting public input as they judged appropriate. Revised discussion papers later formed the basis of chapters of the final report of the Review.

\subsection{Creating the Expert Panel and Technical Advisory Group}

A Technical Advisory Group was appointed comprising a Primary Technical Advisor (Geologist), a Senior Advisor (Petroleum Engineer and shale gas resources/reserves assessment consultant) and a Special Advisor (Economist).

Panellists were nominated by stakeholders and appointed in the following categories of expertise:

- Hydrogeology 
- Water quality management/wastewater treatment

- Oil and gas engineering (focus on shale gas engineering)

- Climate science

- Environmental management

- Economics

- Public health

- Environmental psychology

- Community engagement

- Knowledge of Aboriginal wisdom

- Legal expertise (including Aboriginal law)

Sixty-nine individuals were nominated by stakeholders for inclusion in the panel. Nominees were sorted into categories based on their most relevant area of expertise. Nominees were ranked in each category based on their qualifications and the top candidates were selected to serve on the Panel.

\subsection{Review Principles}

The following six general principles were applied during the review:

1) No Preconceptions. Panel members agreed to abide by a Code of Conduct and no assumptions were made regarding the final outcome of the review process.

2) Legitimacy of All Views. All public commentary and all submissions received by the Panel were accepted as legitimate, except on rare occasions when commentary was rude or disrespectful. 
3) Transparency. A public record of all formal submissions received by the Panel was made available, minutes of meetings were published, thirteen public meetings were held and the Panel Chair was accessible for all media inquiries.

4) Evidence Based. Relevant scientific, technical and other literature was scrutinized and summarized in the review. Technical expert advice was sought and considered as well as evidence provided by stakeholders.

5) Interdisciplinarity. Panel members acknowledged the different world views, disciplines and experience of the other panel members yet were able to collaborate effectively during panel deliberations, writing and drafting of recommendations.

6) Precautionary Approach. Principle 15 of the final declaration of the UN Conference in Environment and Development was applied during the review: "where there are threats of serious or irreversible damage, lack of full scientific certainty shall not be used as a reason for postponing cost-effective measures to prevent environmental degradation." (UN, 1992).

\subsection{The Public Engagement Process and Sequence}

Following the establishment of a project team, appointment of the Panel and in accordance with the original published list of opportunities for engagement, the Panel scheduled the following opportunities for public participation in the review:

- Two informational public meetings

- The release of ten discussion papers

- Convening three online discussion forums 
- Hosting eleven public meetings across the province on preliminary findings and recommendations

All Panel meeting minutes were posted on the project website as soon as they were available and registered stakeholders received regular updates on project schedules and upcoming opportunities for engagement via email.

\subsection{Development of the Final Report and Recommendations for Government}

The final 387 page report comprised an executive summary, an introduction, ten chapters detailing particular aspects and impacts of the technology, and a final chapter reprising the entire report, presenting a summary risk matrix (reproduced as an Appendix to this paper) and recommendations to government. In common with academic practice, the final content of chapters authored by panellists and consultants remained their prerogative and did not require full consensus of all panel members. However the executive summary, introduction and final chapter, including recommendations, did require full consensus.

\section{Results}

\subsection{Results of Public Participation}

Twenty two stakeholders provided feedback on skill sets to be incorporated into the selection process for panellists. Forty seven stakeholders recommended sixty nine candidate Panellists and eight firms submitted bids for technical advisory work.

Formal written submissions to the Panel were received from 215 citizens, ten professional organizations, six environmental organizations, three industry associations, two 
municipalities and two community organizations for a total of 238 unique written submissions.

The overwhelming majority of the written submissions to the review came from individual citizens expressing concerns over the practice of hydraulic fracturing rather than support for it. This was somewhat consistent with public polling data (CRA, 2013 and 2014) which suggested that a majority of Nova Scotians opposed the practice, even with strict regulations in place.

During the period allowed for submission of written evidence, stakeholders also submitted material on hydraulic fracturing and its associated activities and technologies from a wide range of sources. More than two hundred journal articles and reports, and hundreds of news articles, websites, videos and other material were submitted and posted on the review website.

Ninety six stakeholders submitted comments on discussion papers for a total of 170 unique contributions of feedback on discussion papers (see Table 1). Based on feedback from fellow panellists and the public, lead authors revised their papers in various ways e.g. by drawing attention to new literature, addressing misunderstandings or rewriting sections to make information more detailed or clearer to the public. The revised version of their discussion paper was then circulated for final acceptance as a chapter in the final report. Insert Table 1 about here.

Approximately 65 people attended the two informational public meetings and over 1200 people attended eleven public meetings to discuss preliminary conclusions of the review; 
these meetings were held across the province. All of the questions and comments from the meetings were recorded and shared with the Panel. The most frequently asked questions from the public meetings were included as a table in the final report. That table included a list of short answers and links to further information on the subject within the report.

The number of registered stakeholders reached 290 by the close of the review. All stakeholders received regular email updates on progress. Numbers of registered stakeholders by category are listed in Table 2 .

Insert Table 2 about here.

The review did not present findings on outreach to Aboriginal communities as that work was scheduled for a future time. However the report did explicitly recognize the advice offered by members of: the Assembly of Nova Scotia Mi'kmaq Chiefs (ANSMC); the Assembly's Hydraulic Fracturing Committee; the Native Council of Nova Scotia; and the Intergovernmental Affairs Office of the Maritime Aboriginal People's Council (Maclntosh, 2014b).

\subsection{Research Findings}

\subsubsection{Economic and Employment Impacts}

The Panel's geological analysis (Hayes and Ritcey, 2014) led to the development of four scenarios to describe plausible outcomes should hydraulic fracturing proceed in Nova 
Scotia: from zero commercial development through to 20,000 wells developed in five basins over a period of 60 years (Gardner and Hayes, 2014). See Table 3.

Insert Table 3 about here.

The sedimentary basins of onshore Nova Scotia are prospective for oil and gas in unconventional reservoirs. The essential elements: thick unconventional reservoir rocks (rocks with very low permeability, such as shales or highly-cemented sandstones) and organic materials to generate oil and gas are present and widespread. As knowledge of the sedimentary rocks and hydrocarbons in these basins was extremely limited, it was very difficult to quantify potential, or even to rank the basins in terms of overall prospectivity; more exploration, and particularly more deep wells targeted to investigate unconventional reservoirs, would be required.

In the 'lower medium case' (4000 wells developed over 40 years) the Panel's economic assessment estimated annual investments of around $\$ 1 \mathrm{bn}$ and approximate steady state employment of between 750 and 1500 full time equivalent (FTE) direct employees. Approximately one third of the $\$ 1 \mathrm{bn}$ annual spending by the industry under this scenario would be local (Nova Scotia) content i.e. locally contracted goods, services and employment.

There are very few empirically grounded, peer reviewed economic studies of regional economic impacts of natural gas development, and grey literature studies show a wide variety of estimates of job creation resulting from unconventional gas and oil development 
in the US, from less than four direct jobs to more than 30 jobs created per well drilled over a seven year period (Mauro et al., 2013).

Pennsylvania averaged 1650 new wells drilled per annum in the three year period 20102012 and averaged direct employment in the shale gas and related industries of more than 23,000 over the same period (i.e. 14 direct jobs per new well drilled). This represents a three year 'snap shot' of the US shale gas industry characterised by a rapidly expanding development model. This may or may not be sustainable or representative depending on the longevity of well production and other technical factors. In addition it has been estimated that one indirect 'non-mining job' may be created for every 'mining job' in the US shale gas industry (Weber, 2014).

Based on Canadian industry standards, the Gardner and Hayes (2014) estimate for potential direct job creation in Nova Scotia was 750-1500 FTE employees in the lower medium case i.e. 7.5-15 jobs per new well drilled at steady state. These estimates envisaged the relatively slow development of an industry over a number of decades. Thus a greater level of stability of employment could be established in Nova Scotia compared to that typically associated with the US shale gas industry. It is interesting to note that the Gardner and Hayes estimates were comparable with the empirical data for Pennsylvania and well below more optimistic claims (Mauro et al., 2013). If we add the multiplier suggested by Weber (2014), the number of total jobs in the lower medium case may be estimated as 1500-3000 at steady state assuming a 40 year timescale for development and production. 
It was not possible to precisely estimate how many of these jobs would be available to local people, versus how many would be taken by out of province workers for each stage of development given uncertainties over geographic scope and implementation timescales. However, applying Canadian industry standards the Panel was able to calculate a range of likely local content (including local contracting and employment opportunities) as follows: geological assessment: 25-30\% locally contracted; exploration: 30-35\%; hydraulic fracturing: 20-25\%; and development: $30-35 \%$. Local content in production and abandonment activities would be highly dependent on the timescales over which the activities extended but in an established industry extending over decades it is likely that most of the routine production and abandonment activities would be undertaken by existing or incoming settled workers (Gardner and Hayes, 2014).

A number of stakeholders to the process, and indeed the Panel itself noted that an unfortunate public policy dilemma arises in the comparative assessment of benefits and costs associated with the unconventional oil and gas industry. It is relatively simple to measure economic benefits of the industry in terms of spending, employment and royalties because there are well established industry standards backed by empirical data. However there is very little in the peer reviewed literature on costed externalities because the industry is so young. A further complication is that externalities will inevitably be highly specific to jurisdiction, geography and demographics.

Nonetheless, the Panel drew attention to a range of potential, if presently unquantifiable externalities i.e. economic costs that could accrue to local communities or the province. 
Externalities may include negative impacts or costs incurred through: water resource use; transportation and road use; chemical spills; wastewater storage and treatment; damage to drinking water; adverse impacts on human and environmental health; and the costs of regulation (Gardner and Hayes, 2014). There may also be displacement activities in other sectors of the economy e.g. tourism and agriculture, through 'crowding out.' It may be noted that in a series of US case studies, the Multi-State Shale Research Collaborative (2014) extended this list to include impacts on the educational system, the emergency health care system and the criminal justice system.

Against the problem of negative externalities may be set i) the greater spending abilities of municipalities and Aboriginal governments and councils through increased direct revenues and benefits; and ii) the potential availability of some share in provincial royalty payments perhaps as much as $\$ 150 \mathrm{~m}$ per annum in the lower medium case $(\$ 750 \mathrm{~m}$ per annum in the maximum case).

Given the somewhat speculative nature of the estimates of economic impacts the Panel noted that potential benefits and costs (including externalities) would need to be modelled in greater detail for identified geographies as a future research priority. And certainly economic, social, community health and environmental impacts would all need to be assessed within rigorous Health, Social and Environmental Impact Assessments before development could occur. The Panel also observed that potentially affected communities would need to be confident that identified benefits would really accrue and that any social, community, health, economic and environmental costs and externalities would be 
adequately estimated, minimised or compensated before giving their permission to proceed.

\subsubsection{Public Health, Community and Environmental Impacts}

As noted earlier (Methods), Panel members and consultants conducted detailed 'state of the art' assessments of the range of impacts of hydraulic fracturing and its associated technologies with respect to public health (Atherton, 2014), community (Dalton, 2014), water (Gagnon, 2014) and well integrity (Dusseault, 2014). Consistent with the analysis of the Council of Canadian Academies (2014) and the recommendations of Jackson and coworkers (2014), these assessments all confirmed the need for further research, but in no case did they identify hazards that were either catastrophic or not amenable to appropriate levels of monitoring, risk mitigation and regulation. In common with other industrial technologies, hydraulic fracturing and its associated activities and technologies has the potential to bring both benefits and harms to individuals, communities, and populations.

For example, economic growth, improved energy security, and a shift away from primarily imported coal and oil based generation may all indirectly improve population health. Conversely physical risks associated with hydraulic fracturing may include potential exposures to toxic materials through contamination of drinking water sources and atmospheric exposure especially during periods of more intensive industrial activity (e.g. involving drilling) and relating to increased emissions from transportation. And psychological and social disruption may represent hazards for mental health, for example precipitated by noise or light pollution (Atherton, 2014). 
Consistent with the analyses of the Report of the Chief Medical Officer of New Brunswick (Cleary, 2012), a review by Public Health England (Kibble et al., 2014), and a report by the European Parliament (2011), Atherton (2014) concluded that a number of the potential long term and cumulative public health impacts of hydraulic fracturing and its associated activities and technologies are unknown at the present time. Thus, as advocated by Adgate and co-workers (2014), there would be a clear need to put in place comprehensive baseline health and environmental monitoring alongside management and mitigation (risk reduction), strict regulations and enforcement.

The Panel noted that it is too early to predict what will be the long term impacts on communities of unconventional gas and oil development in different jurisdictions around the world (Dalton, 2014). Case studies on specific communities are only just beginning to emerge in the peer reviewed and grey literatures, even in those areas most subject to intensive development (e.g. Multi-State Shale Research Collaborative, 2014; Perry 2012 and 2013). Thus, there is an urgent need for serious empirical research in this area (Jacquet, 2014).

In response to uncertainty and in support of the development of a 'community permission to proceed' mechanism for any future onshore unconventional oil and gas development in Nova Scotia, Dalton (2014) summarised potential positive and negative community effects of unconventional gas and oil and other energy development based on the work of Brasier et al. (2011) and related this to a range of public participation goals which would be important to consider in any future work in the province. 
Gagnon (2014) described the potential impacts on water resources and water quality of hydraulic fracturing and its associated activities and technologies, relating those impacts to known public concerns and Nova Scotia policy on water resource protection and management.

Drinking water quality management practices in the province were described with specific reference to potential contaminants arising from hydraulic fracturing and its associated processes (including wastewater treatment and disposal). Gagnon (2014) discussed water resource use issues related to the practices of fracturing and wastewater treatment and disposal. He concluded that if effective prior modelling of the resource and proper monitoring, regulation and enforcement were in place, there would be no reason to fear catastrophic risks related to hydraulic fracturing with respect to threats either to water quality or water resource use.

Gagnon (2014) concurred with the Council of Canadian Academies (2014) which reported that the most relevant infrastructure risks that unconventional gas and oil development and related operations pose to surface water and groundwater stem from three sources: i) accidental spills of chemicals, oils, drilling muds, and fracture fluids during transportation, storage, or use; ii) spills of condensates (where these are present) or flowback water from the producing well; and iii) inadequate storage, treatment, or disposal of flowback water, which includes both fracturing fluids and saline formation water, and leaks from surface storage ponds or other storage facilities. 
Well integrity was discussed by Dusseault (2014), who noted that issues of well integrity are central to our understanding of some of the most significant long term risks to the environment arising from hydraulic fracturing and its associated processes. Consistent with the work of the Council of Canadian Academies (2014), Dusseault also noted the deficiency of data on long term well integrity or the effectiveness of current management practices e.g. on well completion or decommissioning.

Dusseault (2014) discussed questions of well design, construction, operation, completion, assurance of well integrity and regulatory guidelines, linking these topics to developing industry best practices. He discussed well integrity during production with specific reference to gas migration and leakage, and described a range of potential sub-surface contamination pathways noting the risks of each (i.e. potential frequency and impact), paying particular attention to the concerns of stakeholders on issues such as groundwater contamination and contributions to climate change e.g. through fugitive emissions.

The problem of leaking wells through gas migration both in production and after decommissioning was recognised and the importance of effective long term management, baseline and ongoing monitoring and regulation was stressed. Due to lack of knowledge regarding long term material resilience in deep wells, the potential longer term liabilities of future gas leakage into the atmosphere or seepage into local groundwater could not be calculated; this emphasises the need for effective long term monitoring as well as the local modelling of risks. 
The Panel noted that systematic air quality measurements would need to be taken prior to drilling and hydraulic fracturing as well as during and after operations in order to better understand air emissions and impacts during the full life cycle of production (Moore et al., 2014), so that human health and climate impacts could be fully understood.

There remain significant uncertainties surrounding the climate impacts of increased reliance on unconventional gas development, distribution and use, which are contingent on modelling assumptions and broader climate change policies (Newell and Raimi, 2014). But consistent with a precautionary approach, the Panel recognised that both the Intergovernmental Panel on Climate Change (2014) and the Council of Canadian Academies (2014) concluded that with effective control of emissions a case can be made for natural gas as part of a transition strategy for a lower carbon future.

\subsubsection{Summary of Identified Hazards and Risks}

Throughout the review the Panel was able to demonstrate a high level of congruity between its research and the types of hazard identified by 279 public submissions to the Nova Scotia Department of Energy (2011), hazards identified in 238 unique formal submissions to the review (Mauro, 2014), hazards described in 170 separate items of feedback on published discussion papers (Verschuren Centre, 2014a), concerns expressed by individuals in public meetings attended by more than 1200 people, and hazards identified in the literature (Council of Canadian Academies, 2014; Jackson et al., 2014). What is more challenging is how to reconcile the way in which the frequency and severity of risks are assessed and deemed acceptable (or unacceptable) by different publics and professional scientists. 
However, based on the foregoing, the Panel was able to summarise and synthesise the risks of hydraulic fracturing associated with the potential development of unconventional oil and gas resources in Nova Scotia, and relate those risks to implications for risk management and effective regulation and enforcement. An Appendix to this paper summarises the Panel's overall assessment of sixteen hazards and their associated risks identified throughout the Panel's research and public engagement activities.

\section{Discussion}

The management of risk and the social dynamics of risk perception by the public represent significant challenges for policy makers and corporations alike who need to establish public trust (Cvetkovich, 2013; Renn, 2008). Equally challenging are questions of how to effectively communicate risk information to citizens (Fischhoff, 1995; Slovic, 1987 and 2000).

It has been known since the 1950s that the public perception of health and environmental risks is subject to significant social and psychological influence (Frewer, 1999). Sandman (1987) noted that principles such as voluntariness (self-imposed risk), control (personally managed risk) and fairness (equitably distributed risk) have a significant positive impact on risk acceptance.

Unquestionably, the topic of hydraulic fracturing is fast becoming one of the defining challenges for modern society in terms of risk assessment, risk perception and risk communication, with all the attendant socio-political implications and "threat dynamics" 
that are associated with the emergence of significant concerns with the technology (Jaspal and Nerlich, 2014). The development of unconventional gas and oil resources has many elements that have been identified as problematic in the literature: unfamiliarity, the external and potentially unfair imposition of risk, lack of community or individual control and the perception of benefit-taking by a large industry (Gupta et al., 2012). To these concerns may be added recent observations directly relevant to hydraulic fracturing that suggest "the threat of disruption to place-based identities may spur oppositional behaviour" (Jacquet and Stedman, 2014).

Because of the danger of fundamental polarisation of communities that can occur on the question of shale gas exploitation (Schafft et al., 2013) - often linked to density of drilling and place-related threat dynamics - researchers have advanced ideas for new approaches to risk governance for the industry (North et al., 2014; Sidortsov, 2014).

Clearly, on issues as complex and polarising as hydraulic fracturing, it is essential to address questions of equity, trust and power with respect to risk perception and management (Slovic, 2000). As Frewer (1999) noted: “Ethical concerns, trust and distrust (in scientific institutions, risk regulators and information providers) and perceptions of social exclusion from risk-management processes should be incorporated into theoretical models used to explain the evolution of public resistance to emerging technologies". Frewer also stressed the importance of involving the public in risk-management processes as potentially the optimum means to redress issues "associated with perceptions of social exclusion". 
Of relevance to the situation in Nova Scotia was the inescapable observation based on public submissions to the review that opponents and supporters of hydraulic fracturing for the development of unconventional gas and oil resources represent very different and in some cases fundamentally conflicting worldviews.

Evidence from the U.S. (Boudet et al., 2014) suggests that in one study "women, those holding egalitarian worldviews, those who read newspapers more than once a week, those more familiar with hydraulic fracturing, and those who associate the process with environmental impacts are more likely to oppose fracking." Conversely, supporters "tend to be older, hold a bachelor's degree or higher, politically conservative, watch TV news more than once a week, and associate the process with positive economic or energy supply outcomes."

We know from independent public polling (CRA, 2013; Nova Scotia Commission on Building Our New Economy, 2014) that in common with the situation in many Canadian jurisdictions, Nova Scotians were divided on the issue of hydraulic fracturing. But, consistent with the recommendations of Theodori and co-workers (2014), the Panel hoped to create the conditions under which all participants in the debate might be informed by a broader base of knowledge and would be supported in their expectations of a high level of engagement and exchange with the analysis in the final report (Atherton et al., 2014).

\section{Conclusions and Policy Implications}


In its report to the Nova Scotia Minister of Energy in August 2014, the Panel concluded that the Province of Nova Scotia was not ready to embrace hydraulic fracturing, primarily because of the absence of trust in industry and government and the lack of a geographically grounded social licence (Atherton et al., 2014). Further geographically specific research would be needed on all likely impacts of the development of unconventional gas and oil, particularly with respect to better identifying and quantifying benefits and costs to particular communities that might be impacted.

Based on fuller knowledge of how predicted benefits and costs would play out over the short, medium and long term, the Panel believed that communities would be in a better position to judge the acceptability to them - or otherwise - of any future unconventional gas and oil development in their immediate environment. The Panel reinforced this by recommending that the provincial government develop a 'community permission to proceed' mechanism, consistent with Sandman's (1987) principles of voluntariness (selfimposed risk), control (personally managed risk) and fairness (equitably distributed risk).

The report detailed 32 additional recommendations that would become relevant if the Province and its Aboriginal communities and municipalities decided to pursue the technology.

The process described in this paper was comprehensive, inclusive and characterised by high levels of transparency, public participation and robust debate which undoubtedly enhanced the quality of the final report and its recommendations. Immediate public commentary on the report submitted to government was generally favourable from Aboriginal communities, 
municipalities, environmental groups, industry and media commentators (Verschuren

Centre, 2014b). This provides preliminary evidence for the effectiveness of the consensusbuilding methodology applied. To that extent the process may be deemed to have been somewhat successful as an early example of the kind of inclusive policy-making processes advocated by North and co-workers (2014).

The panel specifically avoided recommending any measure that might postpone or inhibit processes of societal learning. However, within one week of receiving the report, the Nova Scotia Minister of Energy announced his intention to legislate a ban on hydraulic fracturing. ${ }^{2}$ The speed of the Minister's decision effectively precluded more systematic qualitative or quantitative assessments of stakeholder reactions either to the Panel's process or to its report. Of course it would be possible to conduct such research if a future Minister determined that he or she wished to proceed with the recommendations of the review at a later date.

In late 2014 the Nova Scotia government duly passed a law stating that "No person shall engage in high-volume hydraulic fracturing in shale formations unless exempted by the regulations for the purpose of testing or research". ${ }^{3}$ The legislative process resulted in a repolarisation of opinion across political parties and between industry and environmental organisations, both sides voicing criticisms of the legislation. ${ }^{4}$ Subsequently, the

\footnotetext{
${ }^{2}$ Erskine, B (2014). Nova Scotia to ban fracking. Chronicle Herald $3^{\text {rd }}$ September 2014. Available from: http://thechronicleherald.ca/business/1233818-nova-scotia-to-ban-fracking. Accessed $11^{\text {th }}$ April 2015. ${ }^{3}$ Act to Amend Chapter 342 of the Revised Statutes, 1989, the Petroleum Resources Act. Available from: http://nslegislature.ca/legc/bills/62nd 2nd/1st read/b006.htm. Accessed $17^{\text {th }}$ January 2015.

${ }^{4}$ Chronicle Herald Editorial $11^{\text {th }}$ September 2014: Fracking ban hastiness backfires in Nova Scotia. Available from http://thechronicleherald.ca/editorials/1235702-editorial-fracking-ban-hastiness-backfires-in-novascotia. Accessed $17^{\text {th }}$ January 2015. Collyer, D., 2014. Nova Scotia should revisit fracking ban. Canadian
} 
neighbouring province of New Brunswick also announced it would legislate to ban the practice of hydraulic fracturing. ${ }^{5}$

This paper has argued that the complexity of regulating and developing unconventional oil and gas resources requires sophisticated policy development which lends itself to processes of continued research, societal learning and risk assessment in order that benefits and risks can be weighed properly at the relevant community and governmental levels (North et al., 2014). In this respect, hydraulic fracturing suffers from many of the same 'wicked' public policy challenges as renewable energy development where social license may also be difficult to achieve in the absence of sensitive and inclusive policy-making (Stokes, 2013).

At a more fundamental level, and consistent with the recommendations of Small et al. (2014), the public participatory and independent scientific review process described here also suggests that shifts in risk governance and democratic practice may be required prior to natural resource development in jurisdictions where there is polarisation of opinion and low trust in industry and government. But consistent with the observations of Turnpenny and co-workers (2009), and as was observed by the media in this case, ${ }^{6}$ there is no guarantee

\footnotetext{
Association of Petroleum Producers. Available from: http://www.capp.ca/aboutUs/mediaCentre/CAPPCommentary/Pages/Nova-Scotia-fracking.aspx Accessed $17^{\text {th }}$ January 2015.

CTV Commentary $6^{\text {th }}$ October 2014: Fracking ban bill is badly flawed, environmental coalition says. Available from: http://www.ctvnews.ca/politics/fracking-ban-bill-is-badly-flawed-environmental-coalition-says1.2041226\#ixzz3PsKQC963 Accessed $17^{\text {th }}$ January 2015.

${ }^{5}$ Government of New Brunswick (2014). Government introduces moratorium on hydraulic fracturing in New Brunswick. Available from: http://www2.gnb.ca/content/gnb/en/news/news release.2014.12.1404.html. Accessed $17^{\text {th }}$ January 2015.

${ }^{6}$ Chronicle Herald Editorial $3^{\text {rd }}$ September 2014: No energy leadership in N.S. fracking fumble. Available from: http://thechronicleherald.ca/editorials/1233890-editorial-no-energy-leadership-in-ns-fracking-fumble.

Accessed $17^{\text {th }}$ January 2015.
} 
that political decisions will follow the logic of processes such as we have described in this paper, however well designed and executed. 


\section{Acknowledgments}

The authors wish to thank the hundreds of stakeholders who contributed their knowledge and insights to the review described in this paper, the consultants, advisors and graduate and undergraduate researchers who supported the research, and the overwhelming majority of Canadian journalists, broadcasters and commentators who endeavoured to cover the process described here in a considered and fair way. The research was commissioned by the Nova Scotia Department of Energy and executed by the Verschuren Centre for Sustainability in Energy and the Environment at Cape Breton University. We are grateful for the insightful comments of two anonymous reviewers.

\section{References}

Adams, M., Wheeler, D., and Woolston, G., 2011. A participatory approach to sustainable energy strategy development in a carbon-intensive jurisdiction: Case of Nova Scotia. Energy Policy 39: 2550-2559.

Adgate, J.L., Goldstein, B.D and McKenzie, L.M., 2014. Potential public health hazards, exposures and health effects from unconventional natural gas development. Environmental Science \& Technology 48, 8307-8320.

Atherton, F. (2014). Chapter 4: The protection of public health. In: Atherton et al., 2014. Report of the Nova Scotia Independent Panel on Hydraulic Fracturing. Sydney Nova Scotia: Cape Breton University, 122-139. 
Atherton, F., Bradfield, M., Christmas, K., Dalton, S., Dusseault, M., Gagnon, G., Hayes, B., Maclntosh, C., Mauro, I., Ritcey, R., and Wheeler, D., 2014. Report of the Nova Scotia Independent Review Panel on Hydraulic Fracturing. Sydney Nova Scotia: Cape Breton University.

Boudet, H., Clarke, C., Bugden, D., Maibach, E., Roser-Renouf, C., and Leiserowitz, A., 2014. "Fracking" controversy and communication: Using national survey data to understand public perceptions of hydraulic fracturing. Energy Policy, 65, 57-67.

Canadian Association of Petroleum Producers, 2014. Canada's Petroleum Resources.

Calgary: Canadian Association of Petroleum Producers. Retrieved from http://www.capp.ca/energySupply/canadaPetroleumResources/Pages/default.aspx Accessed December 4, 2014.

Cleary, E., 2012. Chief Medical Officer of Health's recommendations concerning shale gas development in New Brunswick. Retrieved from the Government of New Brunswick website: http://www2.gnb.ca/content/dam/gnb/Departments/hs/pdf/en/HealthyEnvironments/Recommendations_ShaleGasDevelopment.pdf. Accessed December 4, 2014.

Council of Canadian Academies, 2014. Environmental impacts of shale gas extraction in Canada: The Expert Panel on Harnessing Science and Technology to Understand the Environmental Impacts of Shale Gas Extraction. Ottawa: Council of Canadian 
Academies. Retrieved from

http://www.scienceadvice.ca/uploads/eng/assessments\%20and\%20publications\%20 and\%20news\%20releases/Shale\%20gas/ShaleGas_fullreportEN.pdf

Cvetkovich, G., 2013. Social trust and the management of risk. London: Routledge.

Dalton, S., 2014. Chapter 5: Socioeconomic and social ecological impacts on communities. In: Atherton et al., 2014. Report of the Nova Scotia Independent Panel on Hydraulic Fracturing. Sydney Nova Scotia: Cape Breton University, 140-165.

Davis, C., and Fisk, J. M., 2014. Energy abundance or environmental worries? Analyzing public support for fracking in the United States. Review of Policy Research, 31(1), 116.

Devine-Wright, P., 2005. Beyond NIMBYism: towards an integrated framework for understanding public perceptions of wind energy. Wind Energy, 8(2), 125-139.

Dusseault, M., 2014. Chapter 7: Well-Integrity. In: Atherton et al., 2014. Report of the Nova Scotia Independent Panel on Hydraulic Fracturing. Sydney Nova Scotia: Cape Breton University, 193-220.

Environmental Protection Agency, 2014. Hydraulic fracturing background information. Washington DC: USEPA. Retrieved from 
http://water.epa.gov/type/groundwater/uic/class2/hydraulicfracturing/wells_hydro what.cfm. Accessed December 4, 2014.

European Parliament, 2011. Impacts of shale gas and shale oil extraction on the environment and on human health. Strasbourg: European Parliament. Retrieved from http://europeecologie.eu/IMG/pdf/shale-gas-pe-464-425-final.pdf. Accessed December 4, 2014.

Fischhoff, B., 1995. Risk perception and communication unplugged: Twenty years of process. Risk Analysis (15): 137-145.

Frewer, L., 1999. Risk perception, social trust, and public participation in strategic decision making: Implications for emerging technologies. Ambio 28(6), 569-574.

Gagnon, G. 2014. Chapter 6: Impacts on water. In: Atherton et al., 2014. Report of the Nova Scotia Independent Panel on Hydraulic Fracturing. Sydney Nova Scotia: Cape Breton University, 166-192.

Gardner, M., and Hayes, B., 2014. Chapter 3: Development scenarios and potential economic impacts. In: Atherton et al., 2014. Report of the Nova Scotia Independent Panel on Hydraulic Fracturing. Sydney Nova Scotia: Cape Breton University, 96-121. 
Gauthier, M., Simard, L., and Waaub, J.-P., 2011. Public participation in strategic environmental assessment (SEA): Critical review and the Quebec (Canada) approach. Environmental Impact Assessment Review 31(1), 48-60.

Greening, L. A., and Bernow, S., 2004. Design of coordinated energy and environmental policies: use of multi-criteria decision-making. Energy Policy, 32(6), 721-735.

Gupta, N., Fischer, A.R.H., and Frewer, L.J., 2012. Socio-psychological determinants of public acceptance of technologies: A review. Public Understanding of Science 21: 782-795.

Hayes, B., and Ritcey, R., 2014. Chapter 2: The potential oil and gas resources base in Nova Scotia. In: Atherton et al., 2014. Report of the Nova Scotia Independent Panel on Hydraulic Fracturing. Sydney Nova Scotia: Cape Breton University, 71-95.

Heikkila, T., Pierce, J. J., Gallaher, S., Kagan, J., Crow, D. A., and Weible, C. M., 2014. Understanding a period of policy change: The case of hydraulic fracturing disclosure policy in Colorado. Review of Policy Research, 31(2), 65-87.

Holahan, R., and Arnold, G., 2013. An institutional theory of hydraulic fracturing policy. Ecological Economics, 94, 127-134.

Intergovernmental Panel on Climate Change, 2014. Climate Change 2014. Mitigation of Climate Change. Geneva: Intergovernmental Panel on Climate Change. 
Jackson, R.B., Vengosh, A., Carey, J.W., Davies, R.J., Darrah, T.H., O’Sullivan, F. and Pétron, G., 2014. The environmental costs and benefits of fracking. Annual Review of Environmental Resources 39(1), 327-362.

Jacquet, J.B., 2014. Review of risks to communities from shale energy development. Environmental Science \& Technology 48, 8321-8333.

Jacquet, J.B., and Stedman, R.C., 2014. The risk of social-psychological disruption as an impact of energy development and environmental change. Journal of Environmental Planning and Management 57(9), 1-20.

Jaspal, R., and Nerlich, B., 2014. Fracking in the UK press: Threat dynamics in an unfolding debate. Public Understanding of Science, 23(3), 348-363.

Kibble, A., Cabianca, T., Daraktchieva, Z., Gooding, T., Smithard, J., Kowalczyk, G., McColl, N.P., Singh, M., Vardoulakis, S. and Kamanyire, R., 2014. Review of the potential public health impacts of exposures to chemical and radioactive pollutants as a result of the shale gas extraction process. Retrieved from the Public Health England website http://www.hpa.org.uk/webc/HPAwebFile/HPAweb_C/1317140158707

Levin, K., Cashore, B., Bernstein, S., and Auld, G., 2012. Overcoming the tragedy of super wicked problems: constraining our future selves to ameliorate global climate change. Policy Sciences, 45(2), 123-152. 
Maclntosh, C., 2014a. Chapter 9: Regulatory issues. In: Atherton et al., 2014. Report of the Nova Scotia Independent Panel on Hydraulic Fracturing. Sydney Nova Scotia: Cape Breton University, 257-280.

Maclntosh, C., 2014b. Chapter 10: Aboriginal, treaty, and statutory rights of the Mi'kmaq. In: Atherton et al., 2014. Report of the Nova Scotia Independent Panel on Hydraulic Fracturing. Sydney Nova Scotia: Cape Breton University, 281-304.

Mauro, F., Wood, M., Mattingley, M, Price, M., Herzenberg, S., and Ward, S., 2013. Exaggerating the employment impacts of shale drilling: How and why. Harrisburg PA: Multi-State Shale Research Collaborative.

Mauro, I., 2014. Chapter 8: Public participation in the assessment of risk. In: Atherton et al. (2014). Report of the Nova Scotia Independent Panel on Hydraulic Fracturing. Sydney Nova Scotia: Cape Breton University, 221-256.

Moore, C., Zielinska, B., Petron, G., and Jackson, R., 2014. Air impacts of increased natural gas acquisition, processing, and use: A critical review. Environmental Science \& Technology 48, 8349-8359.

Multi-State Shale Research Collaborative, 2014. Case Studies: Assessing the Costs and Benefits of Natural Gas Development. Harrisburg PA: Multi-State Shale Research 
Collaborative. Retrieved from http://www.multistateshale.org/case-studies. Accessed August 4, 2014.

Newell, R.G. and Raimi, D., 2014. Implications of shale gas development for climate change. Environmental Science \& Technology 48, 8360-8368.

Ngar-yin Mah, D., and Hills, P., 2014. Participatory governance for energy policy-making: A case study of the UK nuclear consultation in 2007. Energy Policy, 74, 340-351.

North, D.W., Stern, P.C., Webler, T., and Field, P., 2014. Public and stakeholder participation for managing and reducing the risk of shale gas development. Environmental Science \& Technology 48, 8388-8396.

Nova Scotia Commission on Building Our New Economy, 2014. Now or Never: An Urgent Call to Action for Nova Scotians. Halifax Nova Scotia: Commission on Building Our New Economy.

Nova Scotia Department of Energy, 2011. Internal Hydraulic Fracturing Review: Summary of public comments. Halifax Nova Scotia: Nova Scotia Department of Energy . Retrieved from https://www.novascotia.ca/nse/pollutionprevention/docs/Consultation.Hydraulic.Fr acturing.Review.Public.Comments.pdf. Accessed November 16, 2014. 
Nova Scotia Department of Energy, 2014. Hydraulic Fracturing Review Documents. Halifax Nova Scotia: Nova Scotia Department of Energy. Retrieved from https://www.novascotia.ca/nse/pollutionprevention/consultation.hydraulic.fracturin g.asp Accessed December 4, 2014.

Province of Nova Scotia, 2013. Environmental Goals and Sustainable Prosperity Act Chapter 7 of the Acts of 2007, as amended by 2012, c.42. Retrieved from http://climatechange.novascotia.ca/sites/default/files/uploads/environmental\%20g oals\%20and\%20sustainable\%20prosperity.pdf Accessed April 14, 2015.

Rabe, B. G., and Borick, C., 2013. Conventional politics for unconventional drilling? Lessons from Pennsylvania's early move into fracking policy development. Review of Policy Research, 30(3), 321-340.

Rabe, B.G., 2014. Shale play politics: The intergovernmental odyssey of American shale governance. Environmental Science \& Technology 48, 8369-8375.

Renn, O., 2008. Risk governance: coping with uncertainty in a complex world. London: Earthscan.

Ricci, M., Bellaby, P., and Flynn, R., 2010. Engaging the public on paths to sustainable energy: Who has to trust whom? Energy Policy, 38(6), 2633-2640. 
Sandman, P. M., 1987. Risk communication: facing public outrage. U.S. Environmental Protection Agency Journal: November 1987, 21-22.

Schafft, K. A., Borlu, Y., and Glenna, L., 2013. The relationship between Marcellus shale gas development in Pennsylvania and local perceptions of risk and opportunity. Rural Sociology, 78: 143-166.

Sidortsov, R., 2014. Reinventing rules for environmental risk governance in the energy sector. Energy Research \& Social Science, 1, 171-182.

Slovic, P., 1987. Perception of risk. Science 236(4799): 280-285.

Slovic, P. (ed) (2000). The perception of risk. Risk, Society and Policy Series. London: Earthscan.

Small, M.J., Stern, P.C., Bomberg, E., Christopherson, S.M., Goldstein, B.D., Israel, A.L., Jackson, R.B., Krupnick, A., Mauter, M.S., Nash, J., North, D.W., Olmstead, S.M., Prackash, A., Rabe, B., Richardson, N., Tierney, S., Webler, T., Wong-Parodi, G. and Zielinska, B., 2014. Risks and risk governance in unconventional shale gas development. Environmental Science \& Technology 48, 8289-8297.

Smith, M. F., and Ferguson, D.P., 2013. Fracking democracy: Issue management and locus of policy decision-making in the Marcellus Shale gas drilling debate. Public Relations Review 39(4), 377-386. 
Stokes, L., 2013. The politics of renewable energy policies: The case of feed-in tariffs in Ontario, Canada. Energy Policy, 56: 490-500.

Theodori, G.L., Luloff, A.E., Willits, F.K. and Burnett, D.B., 2014. Hydraulic fracturing and the management, disposal, and reuse of frac flowback waters: Views from the public in the Marcellus Shale. Energy Research \& Social Science 2, 66-74.

Turnpenny, J., Lorenzoni, I., and Jones, M., 2009. Noisy and definitely not normal: responding to wicked issues in the environment, energy and health. Environmental Science and Policy, 12(3), 347-358.

United Nations (1992). Final declaration of the UN Conference in Environment and Development. New York: United Nations. Retrieved from http://www.un.org/documents/ga/conf151/aconf15126-1annex1.htm. Accessed November 17, 2014.

Verschuren Centre (2014a). Correspondence and written submissions. Retrieved from http://www.cbu.ca/hfstudy/resources/correspondence\#.VGIEal50w2w. Accessed November 16, 2014.

Verschuren Centre (2014b). Hydraulic Fracturing Review Website. Retrieved from http://verschurencentre.ca/?page_id=1073. Accessed December 4, 2014. 
Weber, J. G. (2014). A decade of natural gas development: The makings of a resource curse?

Resource and Energy Economics 37, 168-183.

\section{Hydraulic fracturing - integrating public participation with an independent review of the risks and benefits: Tables}

Table 1: List of discussion papers released and number of stakeholders submitting feedback ( $n b$ titles of discussion papers changed when they emerged as chapters in the final report).

\begin{tabular}{|l|l|}
\hline Discussion Paper Title & $\begin{array}{l}\text { Unique } \\
\text { Submissions }\end{array}$ \\
\hline Primer on the Process of Hydraulic Fracturing & 35 \\
\hline $\begin{array}{l}\text { The Potential Oil and Gas Resource Base in Nova Scotia Accessible by } \\
\text { Hydraulic Fracturing }\end{array}$ & 16 \\
\hline Petroleum Operations, Costs and Opportunities in Nova Scotia & 22 \\
\hline Hydraulic Fracturing and Public Health in Nova Scotia & 18 \\
\hline $\begin{array}{l}\text { Potential Socioeconomic Effects of Unconventional Oil and Gas } \\
\text { Development in Nova Scotia Communities }\end{array}$ & 17 \\
\hline $\begin{array}{l}\text { What are the Interactions Between Unconventional Gas Resources and } \\
\text { Water Resources? Input quality and quantity requirements and water } \\
\text { treatment needs and impacts. }\end{array}$ & 19 \\
\hline Energy Well Integrity & 14 \\
\hline $\begin{array}{l}\text { The Environmental Impacts of Hydraulic Fracturing in Nova Scotia - A } \\
\text { public participatory risk assessment }\end{array}$ & 15 \\
\hline $\begin{array}{l}\text { Understanding General Regulatory Issues of Hydraulic Fracturing } \\
\text { Hydraulic Fracturing and the Aboriginal, Treaty and Statutory Rights of the } \\
\text { Mi'kmaq First Nations }\end{array}$ & 3 \\
\hline Total & 170 \\
\hline
\end{tabular}

Table 2: Number of registered stakeholders by category

\begin{tabular}{|l|l|}
\hline Stakeholder Category & Registered Stakeholders \\
\hline Aboriginal Community & 9 \\
\hline Consultant & 27 \\
\hline Environmental Group & 13 \\
\hline Government & 10 \\
\hline Industry & 21 \\
\hline Interested Citizen/Other & 145 \\
\hline Municipality & 5 \\
\hline University Affiliate & 50 \\
\hline
\end{tabular}




\begin{tabular}{|l|l|}
\hline Media & 10 \\
\hline Total & 290 \\
\hline
\end{tabular}

Table 3: Four scenarios of potential unconventional gas and oil development in Nova Scotia (TCF = trillions of cubic feet; NB Canada consumes approximately 3 TCF per annum)

\begin{tabular}{|l|c|c|c|c|}
\hline \multicolumn{1}{|c|}{ Scenario } & $\begin{array}{l}\text { Zero } \\
\text { Development }\end{array}$ & $\begin{array}{l}\text { Lower-Medium } \\
\text { Case } \\
\text { Development }\end{array}$ & $\begin{array}{l}\text { Upper-Medium } \\
\text { Case } \\
\text { Development }\end{array}$ & $\begin{array}{l}\text { Maximum Case } \\
\text { Development }\end{array}$ \\
\hline Basins Developed & 0 & 1 & 3 & 5 \\
\hline $\begin{array}{l}\text { Total Potential } \\
\text { Reserves }\end{array}$ & Not Applicable & 100 TCF & 300 TCF & 500 TCF \\
\hline Recovery Factor & Not Applicable & $10 \%$ & $10 \%$ & $10 \%$ \\
\hline $\begin{array}{l}\text { Recoverable } \\
\text { Reserves per Well }\end{array}$ & Not Applicable & 2.5 BCF & 2.5 BCF & 2.5 BCF \\
\hline $\begin{array}{l}\text { Recoverable } \\
\text { Reserves }\end{array}$ & Not Applicable & 10 TCF & 30 TCF & 50 TCF \\
\hline $\begin{array}{l}\text { Number of } \\
\text { Development } \\
\text { Wells }\end{array}$ & 0 & 4,000 & 12,000 & 20,000 \\
\hline $\begin{array}{l}\text { Development } \\
\text { Phase (Years) }\end{array}$ & Not Applicable & 40 & 50 & 60 \\
\hline
\end{tabular}

Highlights:

We describe a review and public participation process on hydraulic fracturing We discuss the difficulty of reconciling social and scientific assessments of risk Processes of societal learning should be further developed Changes in natural resource governance and democratic process are needed Where trust is very low governments may still be incapable of action 